\title{
Preparing Leaders in Public Health for Success in a Flatter, More Distributed and Collaborative World
}

\author{
John R. Kimberly, $\mathrm{PhD}^{1}$
}

\begin{abstract}
In a world that is rapidly changing, what are the challenges for which leaders in public health in the future need to be prepared, what are the qualities and skills they will need for success, and where will they get the training they require? Addressing each of these questions in succession, this article contends that success in a flatter, more distributed and collaborative world will require a new generation of leaders in public health with new mindsets, an appetite for innovation and interdisciplinary collaboration and a strong dose of political savvy. Faculty, curricula and competencies in academic centers play an important role in this equation.
\end{abstract}

Key Words: Public health leaders, competencies, globalization, biomedical innovation.

Recommended Citation: Kimberly JR. Preparing Leaders in Public Health for Success in a Flatter, More Distributed and Collaborative World. Public Health Reviews. 2011;33:289-99.

\section{INTRODUCTION}

To say that we live in a world that is changing rapidly is, perhaps, to understate the obvious. The economic balance of power is shifting from west to east; climate change is redefining how we think about resource consumption; water is becoming not only a scarce resource but a key element in international relations; the ever-present threat of atomic warfare is intensifying; new developments in artificial intelligence are changing how we think about what is "human"; and bio-medical innovations are changing how we think about "illness" and "health". We are connected more tightly than ever before on a global basis. News of revolution in Tunisia, Egypt, and

\footnotetext{
${ }^{1}$ Henry Bower Professor, Departments of Management and Health Care Management, The Wharton School, University of Pennsylvania.

Corresponding Author Contact Information: John R. Kimberly at kimberly@wharton. upenn.edu; Departments of Management and Health Care Management, The Wharton School, University of Pennsylvania, Philadelphia, PA 19104 USA.
} 
Libya is made as we watch; global economic stability cannot be assumed but must be managed; and, on a much more mundane note, we are in contact instantaneously with friends and colleagues halfway around the world.

In the context of these macro changes, the health needs of populations are evolving and require imagination and forceful, committed leadership to navigate successfully. What do we know about the challenges confronting those charged with leading efforts to improve the health of populations? What are the qualities and skills that leaders in public health will need for success? And where will they get the training they will require? These are the three questions to be addressed in the pages that follow.

\section{THE CHALLENGES THAT LIE AHEAD}

\section{Globalization}

Thomas Friedman first published The World is Flat in 2005. ${ }^{1}$ By "flat" he meant that a variety of forces were leveling the playing field of commerce around the globe and that, as a consequence, significant economic opportunities were opening up for countries such as China and India, countries that, by and large, had previously been inwardly focused. He called these forces "flatteners", and they included the collapse of the Berlin Wall, which allowed people and firms on both sides of the wall to become part of the economic mainstream; the broadening of access to the internet and the proliferation of digitization; the emergence of software protocols that permitted the design and publication of documents that could be both sent and read anywhere; the advent of collaboration on online projects; the proliferation of outsourcing; the transfer of manufacturing and/or other business processes "offshore", that is to another country where cost economies could be realized; the streamlining of supply chains that was enabled by new technologies, of both an information and logistical nature; the development of what he called "insourcing", whereby Company A's employees perform a variety of services for Company B, above and beyond the principal one; the explosion of information availability enabled by the development of powerful search engines such as Google ${ }^{\mathrm{TM}}$; and the commercialization of a variety of personal digital devices that enable access to this information at any time and in any place.

He argued that together, these forces have reinforced one another and have transformed the world of commerce by opening up new opportunities on a truly global scale and enabling countries that had previously been relatively isolated from the economic "mainstream" to participate. Friedman's 
work has both admirers and critics. Pankaj Ghemawat, ${ }^{2}$ for example, argues that while the forces that Friedman discusses are certainly present, he exaggerates their importance, as much of the world of commerce involves transactions that are essentially local. Alan Rugman and Chang Oh make a similar argument in their critique of what they call "Friedman's Follies". 3

Whether one agrees with Friedman or thinks he has pushed his basic arguments too far, there is no question that his book has provoked much reflection and debate, and his metaphor is useful as a springboard for an analysis of leadership challenges in public health. A hallmark of increasing globalization is the increasing openness of national borders to flows-both legal and illegal-of goods and services, financial and human capital, information, and expertise. In the domain of health care, specific indicators include flows of investment capital; of patients; of physicians, nurses and other health workers; of medical technology; of pharmaceutical products; of policy tools and initiatives; of a variety of types of information and expertise; and of diseases such as H1N1 influenza, HIV/AIDS, etc. These flows are increasingly common and increasingly significant, and their consequences, both positive and negative, need to be understood and addressed by leaders in the field.

\section{New Technology}

New technology is revolutionizing care and has the potential to revolutionize public health. Particularly significant is the process of what has come to be called "reverse innovation", 4 the process whereby innovations developed in economically fragile locations are exported to richer ones.

This process reverses what has historically been more commoninnovations are developed in richer countries and are then exported to poorer ones. Innovations developed in poorer countries can be expected to be less costly and to have very large markets, so their potential for export is great. Public health needs of both poorer and richer countries can be addressed by such innovations, as the article cited above suggests. And a parallel logic could be adopted by public health leaders: innovations developed in inner cities might well diffuse to wealthier neighborhoods. The example of a portable, inexpensive electrocardiogram (ECG) machine described by the authors - the GE MAC 400-certainly points to the enormous potential of this "reverse" logic. This machine was developed in India to enable testing to be done in rural areas, but has found markets around the globe. Another example is an oral rehydration solution developed in Bangladesh and used globally to reduce mortality and morbidity from diarrhea. The potential of reverse innovation in public health is enormous. 


\section{Increasing Costs}

Costs of providing health care are increasing rapidly around the globe, and every government is searching for ways to limit continued growth. At the same time, illness and disease, particularly chronic illness and the prospect of pandemics, creates an ever-heavier burden on the institutions that have financial responsibility for caring for affected populations. As budgetary issues become increasingly more complex and intractable, and as everdeeper cuts in funding for health programs are made, vulnerable populations are likely to be among those most immediately affected. Public health leaders will face difficult choices and will be challenged with identifying new ways to deliver services to those in need. Commitment to mission will have to be reinforced at every opportunity in the face of pressures to compromise basic values, and new forms of public/private collaboration will have to be invented.

\section{Biomedical Innovation}

Stem cell research, gene therapy and other initiatives that are pushing the frontiers of medical knowledge promise to result in new, previously unavailable treatments. However, the challenge for leaders in public health is not so much championing the availability of these innovations for the populations they serve as it will be to devote existing resources to the spread of low cost treatments and approaches that are already available but that have not diffused widely. For example, Humphreys and McLellan argue that one of the real challenges in the treatment of substance abuse is getting treatments that are currently available and that have been shown to be clinically effective actually used in practice by those who could benefit from them. ${ }^{5}$ This, they suggest, is more a problem of educating primary care physicians about substance abuse and available treatments than lack of treatments themselves. For leaders in public health, the task will be targeting such opportunities and helping to design approaches to encourage their diffusion. This is as much a managerial challenge as it is a clinical one, and it requires deep knowledge of how the medical system works and the kinds of incentives that influence physician behavior.

\section{Increasing Investment in Health Promotion and Prevention}

As the connections between social conditions and health outcomes become increasingly recognized, initiatives will have to be developed to shift from resources invested in medical care to those invested in health promotion and the prevention of illness. ${ }^{6}$ Although this is hardly a new issue, a number 
of recent developments suggest that increasing investment in health promotion and prevention is likely. One has to go no further than research linking obesity to a variety of negative (and costly) health outcomes to appreciate both the need for such investment and the increasing public awareness of the problem. ${ }^{7}$

\section{LEADERSHIP NEEDS}

The challenges that lie ahead are daunting, all the more so in a world that is rapidly changing. What are the principal issues that need to be confronted as we think about developing and building the leadership talent that will be able to deal effectively with these challenges in public health?

To begin, consider the central argument in Jeremy Rifkin's latest book, The Third Industrial Revolution. ${ }^{8}$ Rifkin argues that the world is confronted by the twin problems of a peak in the availability and use of carbon-based energy sources and a need to switch from these sources to greener, less polluting ones to counteract increasingly destructive effects of global warming, and he argues that the coming together of distributed communication technologies and distributed renewable energies such as hydrogen via an open-access, intelligent power grid heralds the advent of a third industrial revolution. Just as the first and second industrial revolutions were enabled by hierarchical forms of organization, the third industrial revolution will be enabled by less hierarchical and more networked, more collaborative relationships among institutions and more collaboration between organizations, teams and individuals.

Now juxtapose Thomas Friedman's vision of a flatter, less borderconstrained world ${ }^{1}$ and Rifkin's vision ${ }^{8}$ of a more distributed, less hierarchical and hence more democratic economic and social order. At their intersection is a view of the world in which effective leadership will rely less on formal, hierarchical authority and more on ability to motivate and promote collaboration across lines, both visible and invisible, that in an earlier time were largely impermeable. One might argue that this imperative will be particularly central in the world of health care, where historically rigid professional distinctions are already beginning to blur, in part because of the democratization of information and the attendant consequence of demystification of professional rank. 


\section{PARADIGMATIC SHIFT}

If, as Paul Starr argued, ${ }^{9}$ the early and middle decades of the $20^{\text {th }}$ century witnessed the increasing sovereignty of the medical profession and the concomitant rise of corporate forms of organization in medicine and health care, one might argue that in the early part of the $21^{\text {st }}$ century we are seeing signs that these two trends have peaked and are being replaced by greater involvement by non-physicians in the provision of care and by communitydriven as opposed to corporate-dominated initiatives in the promotion of health as opposed to the curing of illness. An example of the former is the recent extension to nurses of the right to administer anesthesia to patients under certain conditions, a function that historically was the exclusive province of physicians, while an example of the latter is the effort to attack problems of substance abuse and its health consequences by working with communities and their multiple systems-educational, criminal justice, health care, employment, and housing - to develop broad-based strategies that recognize the complexity and embeddedness of substance abuse problems.

The paradigm shift has two components, each of which involves a fundamental change in how sickness and health and their origins are conceptualized and, ultimately, how they are resourced. The first component is the change from a system focused on illness and medical care to one that is focused on health promotion and illness prevention, while the second is the change from an approach that sees the challenge of health maintenance and promotion as fundamentally one of individual education and behavior change to one that sees the challenge as fundamentally one that needs to be addressed at the community level. The challenge for leaders in public health is to understand and become advocates for these changes, changes which have profound implications for current structures and practices and which will therefore encounter substantial resistance, as we have seen in efforts at health reform in the United States.

\section{IMPLICATIONS FOR FUTURE LEADERS}

To help connect the dots between future challenges and leadership development needs, I felt it was important to hear from the front lines, and so interviewed two contemporary leaders whose careers and achievements suggest both forward-looking thinking and effective execution. As imperfect as this effort may be from a research perspective, it was important to me to get the views of individuals who embody some of the attributes of 
future-oriented leadership despite being deeply connected to the past and the present.

The first, Gary Gottlieb, is currently the President and CEO of Partners HealthCare, an integrated health care system in Boston, Massachusetts that is comprised of the two founding academic medical centers-Brigham and Women's Hospital and Massachusetts General Hospital-as well as five additional hospitals, primary care and specialty physicians, community health centers, and a number of other health related entities. Trained as a psychiatrist, he subsequently received an MBA from the Wharton School of the University of Pennsylvania, and thus has an appreciation for the importance of both the medical and the managerial dimensions of leading a complex health system. The second, Harry Burns, is currently the Chief Medical Officer of Scotland. Trained as a surgeon, he is spearheading an effort to incorporate the latest research on the impact of chaotic social conditions on the health of populations into policies designed to improve population health in his country. Both individuals were generous with their time and their current thinking.

I asked each of them first to identify what they see as the principal challenges confronting public health in the years ahead and, second, to sketch out the leadership qualities they felt were essential if real progress in maintaining and improving the health of populations is to be made. Not surprisingly, given the dramatically different contexts in which they work, their diagnoses of principal challenges differed considerably in detail. However, they converged on two main issues: higher priority needs to be given to addressing the social and economic conditions that produce illness; and the design of systems and incentives currently reflects a curative, medical orientation to health care, whereas in the long run the orientation should incorporate greater investment in health promotion and in prevention. These could both, of course, be considered to be rhetorical flourishes, but when one looks carefully at the evidence, one sees at least the nascent development of increasing resource commitment to both issues at Partners HealthCare and in Scotland.

More interesting for present purposes, however, and perhaps equally surprising, were points of convergence in the qualities they felt future leaders in public health needed in order to be effective. And most interesting to me was the convergence with the macro changes envisioned by Friedman ${ }^{1}$ and by Rifkin. ${ }^{8}$ To wit, and in no particular order of importance:

- An unwavering commitment to the mission of public health and the principles of social justice;

- An interdisciplinary orientation and a deep understanding of the central importance of collaboration and how to make it work in practice; 
- An appetite for innovation and a thirst for the big picture, for seeing beyond the boundaries of the immediate setting;

- A new mindset that appreciates the value and limitations of basic management competencies, that maintains a balanced view of the role of accountability, focus on outcomes, and the need for measurement, and that recognizes the influence of social conditions on the health of populations;

- Political savvy, or the ability to get things done in the face of potentially significant opposition.

Lists are easy to make, as are hortatory statements about what needs to be done. But even if we know that it is unreasonable to expect that any single individual can embody all of the qualities advocated explicitly by Gottlieb and Burns and implicitly by Friedman and Rifkin, we should at a minimum ask what kind of training should be provided and by whom to increase the probability that future leaders in public health will at least be sensitized to what is needed and motivated to attempt to deliver. In so doing, we would be assuming that leaders can be "taught". At the very least, they can be exposed to new ways of thinking and of acting that push the boundaries of their own experience, and hence can "learn" through comparison.

\section{WHAT KIND OF TRAINING?}

A variety of forces, chief among them increasing costs, has pushed providers and payers in the health sector to search for new approaches to managing the myriad transactions and multiple institutions and organizations that together constitute the sector. Whether this search has led them specifically to adopt the perspective of the "New Public Management" ${ }^{10}$ or the "New Public Health", ${ }_{11}^{11}$ or more generally, to develop ad hoc solutions intended to meet the burgeoning need, it is fair to say that "management", in one form or another, has come to health care with, as could be expected, mixed results. ${ }^{12}$ Like it or not, and for better or worse, the logic of managerial efficiency has infiltrated the sector and now permeates discussions of strategy, budget, physician recruitment, technology investment, clinical effectiveness, accountability and quality of services provided. With this development has come an army of what are affectionately known as "the suits", the men and women who have been trained in the techniques and tools of management but most of whom lack any formal medical training. It is these people, by and large, who have been tasked with introducing tools developed in other sectors of the economy to 
the management of hospitals, community health centers and other organizations in the health sector, and their arrival in the pinstripes of managers rather than the white coats of clinicians has often been greeted with all the warmth of an igloo in winter.

The world of providing health services has long been divided into two camps, clinical and administrative, and the oft-noted tensions between the two are born of the different training, missions and values - the thought worlds, in short - of the two professional groups. In the past 25 years, however, there has been a shift in the second group from administrators whose primary responsibility was to maintain order and support the clinicians to managers whose primary responsibility is to insure efficient deployment of organizational resources. This shift in the second group is hardly surprising given the problem of escalating costs, and "the suits" are playing an increasingly significant role in both strategic and operational decisions. The question this shift raises is at what point focus on financial considerations might dominate clinical judgments about what is best for the patient. And what is important in developing future leaders in public health is insuring that they have the background and tools to find the appropriate balance between these two seemingly contradictory pressures. Should they be clinicians, should they have MBAs, should they have MPHs, or something else? What kind of training, in other words, will best meet future challenges, and where will this training be found? Will it be found in medical schools, in business schools, in schools of public health, or, perhaps, in schools of public administration?

The answer is that it could be found in any of those settings if those responsible for educational design and curricular development understand the future contours of the landscape and are able to construct their offerings accordingly. Some direction in this regard is provided by Drs. Burns and Gottlieb, both of whom contend that, first and foremost, a new mindset is required, one that recognizes the cost-saving potential of effective health promotion and prevention, the need to balance infinite health needs and finite resources, and the cost-increasing consequences of the ever-growing incidence of chronic illness. But the challenge here is firmly anchored in the organizations providing the education and training. To what extent will they be able to redesign their offerings to meet what the evolving landscape of public health needs as opposed to simply re-branding what they already do and thus offering a version of what they already know?

Preparing leaders in public health for careers in a flatter, more distributed and collaborative world, and one that is changing rapidly, will certainly require more than a formal academic degree. It requires continual updating 
of skills, continuous learning from experience, and active participation in defining the conditions under which the business of public health plays out. The truly effective leaders in public health in the future will be those who actively manage their careers based on the assumption that what they "know" today is not necessarily what they will need to know tomorrow, and effective educators will be those who understand the career trajectories of successful leaders, who appreciate the interplay of formal education and front-line experience in shaping those trajectories, and who are able to design offerings that are appropriate at different points along the career path of their "students".

This means that academic institutions involved in the business of preparing these leaders will have to be willing to continuously reevaluate the relevance of both the "what" and the "how" of what they do, that is, the content of their curricula and the modes of delivery. It will mean reevaluating the very core of their own technologies, including, but not limited to, the role of the formal classroom in the educational process. It will mean being on top of new technologies that link students virtually and that create a different role for "place" in the educational process. It will mean reconceptualizing, for example, the meaning of an MPH degree and linking educational initiatives more to the development of personal portfolios of "students" than to particular academic degrees. It will mean taking very seriously the incorporation of experience acquired outside of the academic institution into their portfolios systematically and rigorously and building on it. It will require rethinking the already packed sets of requirements for particular degrees in ways that give priority to what students need as opposed solely to what faculty offer. And, more specifically, it will mean exposing them directly to the consequences of underinvestment in public health around the globe and to the unparalleled opportunities to contribute in a meaningful way to improving health by equipping them with perspectives and insights into the new tools and approaches that are available to help them succeed.

The challenge is both daunting and energizing. It means that schools of public health in particular will have to take a leadership role. It means that they will have to be ready to change both the "what" and the "how" of what they do. This will be hard, very hard. But nothing could be more important than the mission of preparing leaders in public health for careers in a flatter and more distributed and collaborative world.

Acknowledgements: The author would like to acknowledge the contributions of Drs. Harry Burns and Gary Gottlieb to this article and would like to thank Jon Chilingerian, Etienne Minvielle and Gérard de Pouvourville for their comments on an earlier draft.

Conflicts of interest: None declared. 


\section{REFERENCES}

1. Friedman TL. The world is flat: A brief history of the twenty-first century. New York, NY: Farrar, Strauss \& Giroux; 2005.

2. Ghemawat P. Why the world isn't flat. Growth strategies. Washington, DC: Heldref Publications; 2007.

3. Rugman A, Oh CH. Friedman's follies: Insights on the globalization/ regionalization debate. Business and Politics. 2008; 10: Article 4.

4. Immelt JR, Govindarajan V, Trimble C. How GE is disrupting itself. Harvard Bus Rev. 2009.

5. Humphreys K, McLellan AT. Brief intervention, treatment and recovery support services for Americans who have substance abuse disorders. Psych Serv. 2010;7:275-284.

6. Phelan JC, Link BG, and Tehranifar P. Social conditions as fundamental causes of health inequalities. J Health Soc Behav. 2010;51 (suppl.): S28-S40.

7. Finkelstein EA, Trogdon JG, Cohen JW, Dietz W. Annual medical spending attributable to obesity: Payer- and service-specific estimates. Health Aff (Millwood). 2009;28:w822-31.

8. Rifkin J. (In Press) The third industrial revolution: The new economics in a distributed, collaborative world. New York, NY: McMillan Palgrave.

9. Starr P. The social transformation of American medicine: The rise of a sovereign profession and the making of a vast industry. New York, NY: Basic Books; 1982.

10. Hood C. The "new public management" in the 1980s: Variations on a theme. Accounting, Organizations and Society. 1995;20:93-109.

11. Tulchinsky T, Varavikova EA. The new public health: An introduction for the $21^{\text {st }}$ century. Amsterdam: Elsevier Science; 2009.

12. Kimberly JR. Managerial innovation and health policy: Theoretical perspectives and research implications. J Health Polit Politics Law. 1982;6:637-53. 